\title{
Influences of Contextual, Cultural Factors and Stakeholders on System Design and Management Analysis in Organizations
}

\author{
Remi Alapo \\ University of Phoenix, Phoenix, Arizona, USA
}

\begin{abstract}
Many businesses and organizations can operate in fast changing environments, which meets the high market demands and stakeholder needs. These successful organizations can adapt to everyday changes in the business climate, based on organizational effectiveness, performance, and good strategic planning. Organizations that have failed have done so because of a lack of a good system design in place. Organizational factors such as the changing business climate, labor trends, diminishing stakeholder interests, and lack of organizational value creation to improving current structures to meet the needs are some examples of why organizations may fail. "System is defined as a set of elements arranged in an orderly manner to accomplish an objective. System, is not a randomly arranged set. It is arranged with some logic governed by rules, regulations, principles, and policies. Such an arrangement is also influenced by the objective the system desires to achieve. Systems are created to solve problems” (Deepak, 2011, para. 1). This paper examines the contextual and cultural factors and stakeholders on systems design and management in organizations by exploring the different major stakeholder group interests that shape the design that is appropriate for a management system.
\end{abstract}

Keywords: system design, management analysis, organizational management, leadership

\section{Influences of Contextual, Cultural Factors and Stakeholders}

A collection of component that work together to realize some objectives forms a system. In a system design, the different components are interconnected with each other and they are interdependent. For example, the human body represents a complete natural system. (Deepak, 2011, para. 6)

Organizational leaders are bound by many factors that affect the economics, political, cultural, educational, social systems that can affect the overall structure and effectiveness of an organization such as an organizational culture that drives value, change, and a custom system design. Organizational leaders can create a well-designed system to drive change and best practices within their organizations which can include such elements as driving change from the bottom up, communicating with stakeholders about system needs and objectives of the desired system.

An organization's culture determines how stakeholders interact with each other to form a relationship that will foster value and growth within the organization (Crossan, Fry, \& Killing, 2005). A competitive organization places pressure on leaders in all departments to be proficient at leading change and more

Remi Alapo, doctor of Management (DM), Organizational Management and Leadership, University of Phoenix, Phoenix, Arizona, USA.

Correspondence concerning this article should be addressed to Dr. Remi Alapo, Social Sciences Dept., Room No. 671, Borough of Manhattan Community College, CUNY, NY 10007, USA. 
responsive at driving performance improvement. The importance of taking a theoretical approach to understanding management requires patience to keep on learning from everyday experiences. Gilbert (2006), stated that an organization that is to remain successful organization continues to seek ways in which to improve its innovation and develop new products and increase efficiency in services that are offered to both their internal and external stakeholders.

\section{Key Characteristics}

The key characteristics and activities which will complete the new organization are efficiency, communication, forecasting strategic decision making, and accountability.

If a system is functioning and separated from the environment, then the system does not have any exchange with the environment or is influenced by environmental changes then it is called an open system. All types of accounting systems, for example, cash, stocks employee attendance are closed systems. Most systems based on rules and principles are closed systems. (Deepak, 2011, para. 8)

Smith, Jennings, and Castro (2005) posited that, organizations must satisfy individual and stakeholder needs. Senior or executive leadership has a responsibility to meet stakeholder interest by being accountable, making strategic decisions, having open communication to communicate issues and decisions to stakeholders as well as employees (Guay, Doh, \& Sinclair, 2004). There must be reciprocity in communication between manager, leaders, employees and other stakeholders. The decisions that organizational leaders make impact the overall goals, structure, and direction in which their organizations are heading. In a management system, organizational culture and the environment or climate in which a business or organization places itself as well as the setting significantly impact employees' productivity level and in the achievement of organizational goals.

\section{Internal and External Relationships}

Both internal and external relationships play a significant role in the way in which a system is designed or managed. An organization's environment is open to both external and internal influences. Open systems are those that require response to changes in the environment such as communication, and forecasting. All open systems have a self-organizing ability to sensitivity in absorbing and adjusting to business and organizational systems (Deepak, 2011). The contextual natures of external and internal influences predispose an organization to continuous tension influenced by predictable and unpredictable events, which subsequently result in a reactive, predetermined, or dynamically appropriate response. Internal and external stakeholder interests should be included in strategic plans and decisions to ensure stake and shareholder support.

Staber and Sydow (2002) stated that organizational effectiveness in a very competitive environment can always be distinguished with a custom system design such as the creation of a best practice in respecting and serving the needs of the communities in which they are located, the type and amount of support that they give to their employees and external stakeholders, support for internal stakeholder innovation and diversity in their current operations and well as in continuous learning. Both customers, suppliers, distributors, and consumers play an important role in system design and management. A good climate or organizational culture usually increases employee morale, increases productivity, and avoids unnecessary organizational malaise between employees and their managers. It is important for managers to have a custom system design that is particular and applicable to their current or existing organizational goals or vision and also have a forecast of future needs and changes through open communication, group decision making, in order to achieve operational goals and 
expected results (Crossan et al., 2005).

\section{Competitive Landscape}

In a globalized environment, the competitive landscape of a system design puts many organizations in positions where they can have a forecast of the demands of their customer needs. Forecasting allows an organization to remain in the competitive landscape where they are able to match their competitions or to redesign or restructure their current business practices based on current market characteristics (Guy, 2004). Understanding market characteristics allows organizational managers to understand how much of an investment to make in their organizations with a vision to create the most cost-effective approaches in their organizations. To remain competitive, managers need to be innovative and create new ideas incorporating new technologies in their organizational design and practices. Such strategic decisions and innovative ideas can include opening communication with employees, braining storming with stakeholders, encouraging creativity within teams to foster new products or services (Hamalainen, Kettunen, Marttunen, \& Ehtamo, 2000).

\section{Strategic Opportunities and Challenges}

Organizations can implement good strategic opportunities if there is proper planning in and a good forecast of future goals, sales, and commitment. Jones (2004) stated that a process in which organizations design and transform their current structures and cultures to increase future internal and external stakeholder value and effectiveness is called organizational system design. Lyden and Wright (1969), stated that organizational leaders in today's age of technological advancement innovation and flatter business environments need to find new ways to deal with the continual and rapid change of globalization. Organizational managers who are faced with major business decisions need to constantly find new ways of meeting the demands of both their internal and external stakeholders, and can be no longer. These leaders devote a substantial amount of effort to developing the strategy, which is the determination of long-range goals and objectives of an organization, and the implementation of courses of action and allocation of resources essential to carrying out these goals. The strategic action plan must be made available so that it is periodically updated (Bolman \& Deal, 2003).

\section{Performance Improvement}

According to Comfort, Sungu, Johnson, and Dunn (2001), organizational performance declines when there are no clear forecast or strategic plans in place to move an organization forward from its current state to the next. The ability to continue information flow, communication, and coordination to integrate operational requirements involves creating an organizational strategic program of action that will access the current organizational performance and increase stakeholder as well as organizational value. Performance strategies provide an organization with tools and steps to address a disruptive event. As in understanding that people have different personalities, organizational leaders in a competitive environment need to understand that organizations environment and their culture have different personalities and characteristics that are needed to increase innovativeness and improve overall performance (Mitroff, 2004).

\section{How Influences Shape the Design of an Effective System Management}

Stakeholders are the life of any organizational management design and system. Without their support or increasing their value by including them in strategic plans and systems designs, many organizations will not be in existence or not have the current values that they have. Major stakeholder groups include both internal and 
external customers such as employees, investors, taxpayers, stockholders, donors, suppliers, business partners, the community in which the business is operating or serving and senior management team or the executive leadership of the organization. Objectives of a management strategy will produce cost effectiveness and improvements in its role as a useful branch of management. Strategy for implementing a management plan is a complex continual process that organizations must improve on by increasing share and stake holder value in their strategic planning and forecasting systems.

According to Kaplan (2005), a successful system's implementation is created when strategy, structure, and systems are tightly integrated to form a custom systems design. A successful system and management design will include opening communication to all stakeholders, evaluating current and future needs and goals, having a projected forecast and including stakeholders in all facets of the management and organizational design, and being accountable. Organizational leaders and managers have an obligation to keep communication open so that their stakeholders can keep abreast of changes, new products, services, issues, strategic decisions that may likely increase or decrease stakeholder value or diminish their interests, accountability in financial reporting included in every facet of their organizational growth.

To increase major stakeholder group value, organizational leaders can inform their stockholders by being open, honest, and accountable in the communities in which they work to increase interest and gain stakeholder trust. Guay et al. (2004), posited that employees need to be informed so that they will know the problems the organization is having. Some organizations collapse because of a lack of communication and because employees are not informed appropriately about company issues until the last minute. Organizations operating in different communities also have a moral obligation to keep their constituents informed of how new business expansion or close down will affect the people in the communities in which they are operating.

Stakeholders can also be influential during a system design by making sure that working towards stakeholder interests and increasing value while encouraging staff to report errors or mistakes in planning that will be detrimental to organization as well as stakeholders needs to be discussed members of their organizations or partners involved in the strategic plan and decision making process (Mitroff, 2004). Leaders influence in the anticipation of an event and being prepared ahead of time or having a system in place that will provide a safe environment so as to avoid the economic loss or human resources of the organization (Boleman \& Deal, 2003). The influence of leaders to not make mistakes when anticipation or preparing for a systems design, is to increase their organizational culture by including major stakeholder groups in their management and planning (Boleman \& Deal, 2003).

\section{Conclusion}

A systems design allows an organization to evaluate its current structure and strategically plan for its future goals by increasing and satisfying stakeholder value and interests. It also assists organizational leaders in communicating current and future business needs to their stakeholders. The contextual and cultural values that hinder the custom management design of an organization have several cultural as well as contextual influences that shape an effective systems design and management. Major stakeholder groups are very influential in a management or system design as they are the added value behind the success of an organization. Their inputs and decisions are very important when organizational managers are making future plans, forecasts on goals and restructuring of their current organizational needs. By including stake and shareholder decisions in forecasts and future organizational plans and strategic decisions, organizations and business entities will add more value 
based strategies to their current goals for a cost-effective value based management system and design.

\section{References}

Bolman, L. G., \& Deal, T. E. (2003). Reframing organizations: Artistry, choice, and leadership (3rd ed.). San Francisco, CA: Jossey-Bass.

Comfort, L. K., Sungu, Y., Johnson, D., \& Dunn, M. (2001). Complex systems in crisis: Anticipation and resilience in dynamic Environments [Electronic Version]. Journal of Contingencies \& Crisis Management.

Crossan, M. M., Fry, J. N., \& Killing, J. P. (2005). Strategic analysis and action (6th ed.). Toronto: Prentice Hall.

Deepak, K. (June 9, 2011). Concept of system analysis design (SAD), need for system analysis, process of SAD, MIS and system analysis. Management Information System.

Guay, T., Doh, J. P., \& Sinclair, G. (June, 2004). Non-governmental Organization, shareholder activism, and socially responsible ethics. Journal of Business Ethics, 52(1), 125.

Guy, P. (summer, 2004). Developing an optimal forecast system: The Klein tools' experience. The Journal of Business Forecasting Methods \& Systems, Flushing, 23(2), 20.

Gilbert, D. (2006, August/September). Never stop learning. British Journal of Administrative Management, 54, 29-31.

Hamalainen, R., Kettunen, E., Marttunen, M., \& Ehtamo, H. (July, 2000). Evaluating a framework of multi-stakeholder decision support in water resource management. Group Decision and Negotiating, 10(4), 331.

Jones, G. R. (2004). Organizational theory, design, and change (4th ed.). Upper Saddle River, NJ: Prentice Hall.

Kaplan, R. S. (2005). How the balanced scorecard complements the McKinsey 7-S model. Strategy \& Leadership, 33(3), 41-46.

Lyden, F., \& Wright, D. S. (1969, March/April). The social psychology of organizations/sociology and modern systems theory organizations in action. Public Administration Review, 29(2), 215-219.

Mitroff, I. I. (2004). Crisis leadership: Planning for the unthinkable. Hoboken, NJ: John Wiley \& Sons Inc.

Smith, C., Jennings, C., \& Castro, N. (2005). Model for assessing adaptive effectiveness development. Journal of Contingencies \& Crisis Management, 13(3), 129-137.

Staber, U., \& Sydow, J. (2002). Organizational adaptive capacity: A structuration perspective. Journal of Management Inquiry, 11(4), 408-424. 